\title{
Are there qualitative differences in reading behavior between dyslexics and normal readers?
}

\author{
REBECCA TREIMAN \\ Wayne State University, Detroit, Michigan \\ and \\ KATHY HIRSH-PASEK \\ Haverford College, Haverford, Pennsylvania
}

\begin{abstract}
This study asked whether the reading behavior of dyslexics differs qualitatively from that of normal children. Thirty-seven children who had been identified is dyslexic (mean age 11 years, 9 months) were matched with 37 normal readers (mean age 8,6 ) on ability to read regular words. The dyslexics' and normals' levels of performance on nonsense words and exception words were strikingly close. Also, patterns of individual differences were similar for the two groups. The results suggest that these dyslexics are delayed in the development of both spelling-sound rules and wordspecific associations. They do not support the view that dyslexics have a specific deficit in the use of spelling-sound rules, or that dyslexics show more extreme individual differences than do normal readers.
\end{abstract}

Reading-even the reading of single words-is a complex skill with several component processes. According to many investigators (e.g., Baron, 1977; Coltheart, 1978), at least two processes are used to identify words. One involves the use of spelling-sound rules, or regular relationships between printed letters and sounds. Readers can take advantage of these relationships by using correspondences between individual letters and individual phonemes, correspondences involving larger units, or analogies (Baron, 1977, 1979). The ability to use spellingsound rules is particularly important for beginning readers, who often encounter unfamiliar words (Jorm \& Share, 1983; Rozin \& Gleitman, 1977). A second process involves word-specific associations, or memorized associations between individual printed words and their pronunciations, their meanings, or both. This process aids performance on familiar words. For morphologically complex words, a third process has been suggested in which words are recognized on the basis of visually regular, meaningful subunits (Freyd \& Baron, 1982; HirshPasek \& Freyd, 1984).

An understanding of component skills in reading can help to specify the source and nature of individual differences in reading ability (see Carr, 1981). In particular, the component-skills analysis of word reading indicates that normal readers differ among themselves in their rela-

Some of these data were presented at the Boston University Conference on Language Development, October 1983. We thank Peggy Ericson and Bea Gattuso for their assistance with the research, and John Castellan for statistical advice. Jon Baron, Tom Carr, and Dick Olson provided helpful comments on a draft of the manuscript. Preparation of the manuscript was aided by NICHD Grant HD18387 to Rebecca Treiman.

R. Treiman's mailing address is: Department of Psychology, Wayne State University, 71 W. Warren Ave., Detroit, MI 48202. tive reliance on the several component processes (Baron, 1979; Baron \& Strawson, 1976). Although all can use both spelling-sound rules and word-specific associations to read single, morphologically simple words, some rely more heavily on spelling-sound rules. These readers are known as "Phoenicians." Individuals at the middle of the continuum show a balance between the two processes, and individuals at the other end, or "Chinese," stress wordspecific associations. Thus, normal readers at the same overall level of performance may differ from one another in their relative reliance on rules versus specific associations.

In this paper, we apply the component-skills analysis of word reading to the study of dyslexics-those children who experience great difficulty in learning to read relative to their peers. The customary definition of dyslexia, and the one that will be adopted here, is a severe difficulty in reading despite normal intelligence, normal quality of schooling, and normal emotional adjustment. This definition is intended to distinguish dyslexia, or specific reading disability, from reading problems that are associated with low intelligence, poor schooling, or emotional problems. Which component or components of the reading process are deficient in children who are identified as dyslexic? With regard to the processes involved in the reading of single, morphologically simple words, three proposals have been put forward. The first (e.g., Jorm, 1979) may be called the "rule-deficiency hypothesis." In this view, dyslexics differ from normals only in their lesser ability to use spelling-sound rules. Their use of wordspecific associations is not impaired. Consequently, dyslexics do as well as normal children with common real words but have difficulty, relative to normals, in the decoding of nonsense words. In the terms introduced above, dyslexics fall at the "Chinese" end of the Phoeni- 
cian-Chinese continuum. The second point of view (e.g., Beech \& Harding, 1984) may be called the "developmental-lag hypothesis." In this view, dyslexics lag behind their peers in the development of linguistic skills in general. Their deficiencies in reading are not confined to one component of the reading process, but affect the use of both spelling-sound rules and word-specific associations. Although dyslexics perform at a low level, they may show the same kinds of individual differences seen among normal children. The third hypothesis (e.g., Boder, 1973) is the "extreme-individual-differences hypothesis." The claim here is that individual differences among dyslexics are more marked than are individual differences among normal readers. Some dyslexics (the majority, according to Boder) have difficulty only with spelling-sound rules. These children, who may exhibit relatively good ability to read common real words together with almost complete inability to decode nonsense words, rely on specific associations to a degree not typical of normal children. They are at the extreme "Chinese" end of the PhoenicianChinese continuum. Other dyslexics use rules well, but have severe problems in the learning and use of wordspecific associations. Such children show an extreme "Phoenician" style. Thus, individual differences among dyslexics are hypothesized to cover a wider range than individual differences among normal readers.

To test which component or components of the reading process are deficient in dyslexics, this paper compares children identified as dyslexic with younger children of the same reading level. Were dyslexics compared with same-aged normal readers, the dyslexics would presumably be found deficient in all aspects of the reading process. Scaling problems and other factors (see Baron \& Treiman, 1980a) would then make it difficult to determine whether the dyslexics' impairment was greater for one component process than for another. Notice that the three hypotheses discussed above make different predictions for the comparison between older dyslexic and younger control subjects. The rule-deficiency hypothesis predicts that dyslexics' reading performance will differ from that of normal controls. Although dyslexics may do as well as controls on common real words, for which word-specific associations can suffice, they should perform more poorly than normal subjects on nonsense words and on other measures of spelling-sound rule use. That is, they should show as a group a more marked "Chinese" pattern of reading performance than do normal readers. The developmental-lag hypothesis makes a different prediction. In this view, dyslexics should not differ from younger normal readers. Since differences between dyslexics and normals are quantitative rather than qualitative according to the developmental-lag hypothesis, the dyslexics' pattern of performance should be indistinguishable from that of the younger controls. Finally, the extreme-individual-differences hypothesis predicts that dyslexics will be more variable in their pattern of reading performance than controls. Although the groups may show comparable mean levels of performance, the dyslexics will be distinguished from the normals by their more extreme patterns of reading performance. Some will show a marked "Chinese" style of reading single words, more extreme than that seen among normals; others will show a "Phoenician" pattern that is beyond the extreme of the normal range.

Surprisingly, relatively few studies have compared dyslexics with younger normal readers in the way suggested above. As Snowling (1980, p. 295) points out, "although reference is often made to the distinctive nature of dyslexic reading behavior, few empirical studies have shown it to be different from that of normal readers." Recently, however, several studies have found evidence that dyslexics differ from younger normal readers in a way that is consistent with the rule-deficiency hypothesis. Snowling $(1980,1981)$ studied children who had been referred to a special program for dyslexics. She compared them with younger children from regular classrooms, matching the groups in ability to read real words. In the first study (Snowling, 1980), the dyslexics, whose ages averaged about 12 years, performed worse than 91/2-yearold control subjects in a task in which they saw a fourletter nonsense word (e.g., SNOD) and had to tell whether or not it matched a spoken stimulus (e.g., "sond"). In the second study (Snowling, 1981), dyslexics also did poorly relative to normals in the oral reading of nonsense words. Similar results were obtained by Bradley and Bryant (1981), DiBenedetto, Richardson, and Kochnower (1983), and Kochnower, Richardson, and DiBenedetto (1983). In those studies, reading-disabled children whose ages averaged about 10 years performed worse than normals in tasks that required them to pronounce nonsense words and regularly spelled real words. This deficiency occurred in the face of equivalent performance on standardized reading tests. Since standardized tests include common irregularly spelled words, for which wordspecific associations may be used, the investigators suggest that dyslexics have difficulty decoding words by means of spelling-sound rules. They do not necessarily have trouble with word-specific associations. Finally, Olson, Kliegl, Davidson, and Foltz (1985), as part of a large study of reading-disabled children, matched 50 older disabled readers (mean age 15.4 years) with 50 younger normal readers (mean age 10.1 years) on a standardized word-recognition test. Both groups performed at approximately the seventh grade level. Olson et al. then compared the groups on a phonological and an orthographic task. The phonological task required children to judge which of two nonsense words (e.g., CAIK, DAKE) sounded like a real word. The orthographic task required them to indicate which of two similar-sounding items (e.g., RAIN, RANE) was a real word. The disabled readers made more errors than the normals on the phonological task but not on the orthographic task. Olson et al. (1985) conclude that, while disabled readers do show substantial individual differences, a "deficit in phonological coding seems to be the most distinctive characteristic of the disabled group ... [and] may be the cause of most severe deficits in reading ability that are not related to low intelligence or poor education" (p. 54). 
Although there appears to be a fair amount of evidence in favor of the rule-deficiency hypothesis, the case is by no means closed. A recent study by Beech and Harding (1984) failed to replicate the finding that poor readers have a specific deficit in decoding words by means of spellingsound rules and in related phonological tasks. Following the procedure of Baron (1979), Beech and Harding (1984) had children pronounce lists of regular, exception, and nonsense words. Regular words, such as BONE, can be read either by word-specific associations or by rules. For nonsense words like YONE, however, rules are useful because children have no preexisting associations. Finally, word-specific associations are important for exception words like DONE. A reliance on rules in this case will produce the incorrect pronunciation, "dōn." If poor readers have difficulty with rules rather than with wordspecific associations, they should do poorly on nonsense words relative to the normals. Their performance on exception words may actually exceed that of the control group if they rely on word-specific associations to compensate for their deficiency in rules. Beech and Harding (1984) compared older poor readers (mean age 9.9) and younger normal readers (mean age 7.2). The two groups scored at the same level on standardized reading tests, both a test involving single words and a test involving passages. Contrary to the rule-deficiency hypothesis, the two groups performed equivalently on regular, exception, and nonsense words, both in latencies and in errors. Also, the poor readers were not deficient relative to normals in tasks such as judgments of rhyme or alliteration that require the phonological analysis of spoken words. This latter result fails to replicate an earlier finding by Bradley and Bryant (1978). Beech and Harding (1984) found that both the older poor readers and the younger normal readers differed among themselves in their relative reliance on rules versus specific associations, as assessed by their patterns of performance on regular, exception, and nonsense words. However, the individual differences did not appear to be more extreme for the poor readers than for the younger controls, as the extreme-individual-differences hypothesis would predict.

Beech and Harding's (1984) results support the developmental-lag hypothesis as opposed to the rule-deficiency hypothesis or the extreme-individual-differences hypothesis. However, a potential problem with their study for present purposes is that their poor readers were of low socioeconomic status and would not have been classified as dyslexic according to a stringent criterion. The present study asked whether the results of Beech and Harding (1984) could be replicated for a sample of children who had been identified as dyslexic.

\section{METHOD}

\section{Subjects}

The 37 dyslexics who took part in this study had been referred to a clinic at the College of Medicine and Dentistry of New Jersey (CMDNJ) for testing and cow. ling. All had been classified as dyslexic because their difficulty in learning to read could not be accounted for by poor vision, poor hearing, low IQ, severe educa- tional deprivation, or severe emotional disturbance. For a child to be included in the dyslexic group, the full-scale IQ (WISC-R) had to be at least 80 , with either the performance or the verbal score greater than or equal to 90 . English had to be the primary language, and neurological disease or classical neurological signs with functional impairment had to be absent. The reading quotient, or the ratio of observed achievement age in reading to expected achievement age, had to be less than or equal to .85 . The sample of dyslexics so chosen had an average age of 11 years, 9 months (range $=8,10-14,4 ; \mathrm{SD}=1,6)$. Their mean grade level on the Gilmore test (Gilmore \& Gilmore, 1968), measuring the accuracy of oral reading of paragraphs, was $2.83(\mathrm{SD}=.82)$. The average grade equivalent on the Woodcock (1973) word-identification test was 3.57 ( $\mathrm{SD}=1.21$ ). All children in the dyslexic group were male.'

The study also included a group of 37 younger normal readers. To select the control group, a large number of children from regular school classrooms were tested using the same procedures used for the dyslexics. The subjects who received the same or close to the same score on the regular word reading list as a dyslexic subject were chosen for the control group. For 29 of the dyslexic-normal pairs, the two children had the same score on regular words; for 4 pairs, the dyslexic read one more regular word than the normal control; and for 4 pairs, the normal reader scored one higher. The normal readers had a mean age of 8 years, 6 months (range = $6,6-10,6 ; \mathrm{SD}=1,1)$. Thus, they were, on the average, 3 years, 3 months younger than the dyslexics. The normal-reader group included 22 males and 15 females. $^{2}$

\section{Stimuli}

All subjects were given the reading test previously used with normal 9- and 10-year-olds by Treiman (1984), which was based on the work of Baron (1979). This test contained 96 items, which were constructed in sets of three. Each set contained a regular word (e.g., BONE), an exception word (e.g., DONE), and a nonsense word (e.g., YONE). The average frequency of the regular words in the Carroll, Davies, and Richman (1971) corpus of reading material for children in grades 3 to 9 was 613. The exception words, with a mean frequency of 2,115 , tended to be more frequent than the corresponding regular words $[\mathrm{t}(31)=1.79, \mathrm{p}<.09]$. The real words were, of course, more frequent than the nonsense words. Thus, if associations built up through experience with specific words determined performance, children should do best on exception words, intermediate on regular words, and worst on nonsense words. The stimuli were divided into three subsets of increasing difficulty for purposes of presentation. This division was based on the grade level at which the words were introduced in the Ginn basic reading series, the Carroll et al. (1971) word-frequency norms, and the authors' judgment. Each item was printed on an index card in large uppercase letters. A complete list of stimuli in the order of their presentation appears in the Appendix.

\section{Procedure}

The items in each subset were presented in the order of regular, exception, nonsense. The experimenter held up each card in turn and asked the child to try to read the item aloud. For regular and exception words, the experimenter also asked the child if each was familiar. For nonsense words, the experimenter explained that the words were not real but asked the child to pronounce them as well as possible. The experimenter did not tell the child whether his or her responses were correct. If a child could read few or no items at one level of difficulty and/or if the child did not wish to continue the test, the items at the next level of difficulty were not presented.

\section{RESULTS}

Table 1 shows the mean number correct on each of the three word types for dyslexics and for normals. As shown 
Table 1

Mean Scores for Dyslexics $(n=37)$ and Normals $(n=37)$ and Results of $t$ Tests for Group Differences

\begin{tabular}{|c|c|c|c|c|c|}
\hline & \multicolumn{2}{|c|}{ Dyslexics } & \multicolumn{2}{|c|}{ Normals } & \multirow[b]{2}{*}{ Group Difference } \\
\hline & Mean & SD & Mean & SD & \\
\hline Number regular words correct of $32(R)$ & 18.86 & 7.44 & 18.89 & 7.45 & Not significant \\
\hline Number exception words correct of 32 (E) & 16.32 & 7.58 & 16.92 & 7.03 & Not significant \\
\hline \multicolumn{6}{|l|}{ Number nonsense words correct of 32} \\
\hline Liberal scoring (NL) & 20.54 & 8.39 & 20.65 & 8.09 & Not significant \\
\hline Conservative scoring (NC) & 15.46 & 6.98 & 15.05 & 6.75 & Not significant \\
\hline Proportion sound-preserving errors (S) & .37 & .21 & .42 & .27 & Not significant \\
\hline Proportion meaning-preserving errors (M) & .06 & .08 & .02 & .04 & $\mathrm{p}<.01$, one-tailed \\
\hline Proportion real word errors (REAL) & .53 & .13 & .43 & .11 & $\mathrm{p}<.005$, one-tailed \\
\hline
\end{tabular}

Note-All nonsignificant differences have $p \geq .20$, one-tailed.

in the table, nonsense words were scored in two ways. The liberal scoring system (previously used in the studies of Baron, 1979; Baron \& Treiman, 1980b; Treiman \& Baron, 1981; and Treiman, 1984) counts nonsense words as correct if they are pronounced by analogy with either the corresponding regular word or the exception word. For example, YONE would be scored as correct if pronounced "yun" (to rhyme with "done") or "yōn" (to rhyme with "bone"). The pronunciation of YONE as "yan" would be incorrect, however, since ONE is never pronounced "an." The conservative scoring system counts nonsense words as correct only if pronounced by analogy with the regular word. In the example, YONE would be correct if pronounced to rhyme with "bone," but not if pronounced to rhyme with "done."

Inspection of Table 1 shows that the dyslexics and the normals, who were matched on ability to read regular words, performed strikingly alike on exception words and nonsense words as well. Contrary to the hypothesis that dyslexics are deficient relative to normals in the use of spelling-sound rules, they pronounced nonsense words as well as did normal readers. This result held true regardless of the scoring system employed. It held for the dyslexics who scored below the median on regular words as well as for the sample as a whole. Also, dyslexics did not do better on exception words than normals. Such a difference would have been expected if dyslexics had achieved their comparable level of performance on regular words by relying more on word-specific associations and less on spelling-sound rules than normals. Thus, there is no sign of the crossover interaction between word type (nonsense vs. exception) and group (dyslexic vs. normal) that is predicted by the rule-deficiency hypothesis. Further, the standard deviations of the exception and nonsense word scores were comparable for the two groups. The dyslexics did not appear to be more variable than the normals, as the extreme-individual-differences hypothesis would suggest.

Table 1 shows several measures of the types of errors that children made in the reading test. Sound-preserving errors are errors on exception words in which the exception word is misread as the corresponding regular word. For example, one might read DONE as "dōn," to rhyme with "bone." The mean proportion of such errors, relative to all errors on exception words, did not differ for the two groups. Since sound-preserving errors correlate with use of rules in reading (see Baron, 1979; Mitterer, 1982; Treiman, 1984; and below), the lack of a difference between dyslexics and normals again suggests that dyslexics are not less likely than normals to use rules. Meaning-preserving errors are errors in which a real word is misread as a semantically related real word. The proportion of such errors, relative to all errors in which regular and exception words were misread as other real words, was low for both dyslexics and normals. The meaning-preserving errors that did occur were similar in sound as well as in meaning to the correct word, as when SAYS was misread as "say" or BLOOD was misread as "bleed." Nevertheless, there appeared to be a group difference in the tendency to make these errors. Sixteen dyslexics made one or more meaning-preserving error, but only nine control subjects did so. The group difference was significant by a paired $t$ test. Differences between dyslexics and normals also emerged in the tendency to make errors that were real words. The mean proportion of all errors on regular, exception, and nonsense words that were real English words was significantly higher for the dyslexics than for the controls.

A final difference between the groups, not shown in Table 1, related to subjects' judgments of the familiarity of the regular and exception words. Dyslexics said that a mean of $25 \%$ of these items were not familiar. Control subjects judged only $15 \%$ as unfamiliar. The group difference was statistically significant $[\mathrm{t}(36)=2.99, \mathrm{p}<.005$, one-tailed]. However, given that a real word was judged to be familiar, the dyslexics were more likely than the normals to read it correctly $[\mathrm{t}(36)=3.55, \mathrm{p}<.005$, onetailed]. The probability of a correct response given that a word was judged familiar was .74 for the dyslexics and .65 for the controls, so that the two groups, in fact, achieved virtually the same numbers of correct responses.

Although the dyslexics and the controls achieved similar mean scores on most measures, the patterns of correlations among the measures might differ for the two groups. For example, the extreme-individual-differences hypothesis would predict that use of rules, as reflected in nonsense word score and proportion of sound-preserving errors, would correlate less highly with the exception-word score for dyslexic subjects than for normal subjects. To investigate these issues, tests for the equal- 
ity of covariance matrices were carried out as recommended by Morrison (1976, pp. 252-253). If the covariance matrices for the dyslexics and for the controls were found not to differ significantly, we might infer that the pattern of correlations for the dyslexics was statistically indistinguishable from that for the controls. We might also infer that the variances of the variables in question were similar for the two groups. Using the five variables of number correct on real words $(R)$, number correct on exception words $(E)$, number correct on nonsense word with liberal scoring (NL), proportion sound-preserving errors (S), and proportion real-word errors (REAL), the covariance matrices for the dyslexics and the normals were statistically indistinguishable $\left[\mathrm{x}^{2}(15)=19.87, \mathrm{p}>.15\right]$. The result was the same when the conservative measure of performance on nonsense words (NC) was substituted for the liberal measure. The equality of the covariance matrices indicates that the pattern of correlations among these variables is similar for the dyslexics and the controls.

Only when the variable of proportion of meaning-preserving errors (M) was included did a statistically significant difference emerge between the covariance matrix for the dyslexics and the covariance matrix for the controls. The chi-square values with 15 degrees of freedom were 42.70 for the variables $\mathrm{R}, \mathrm{E}, \mathrm{NL}, \mathrm{S}$, and $\mathrm{M}$ and 43.84 for the variables R, E, NC, S, and M ( $p<.005$ for both). The difference apparently arose because $M$ showed significant negative correlations with R, E, NL, and S (and a nonsignificant negative correlation with NC) for the control subjects. For the dyslexics, the correlations were in a negative direction but were not (with the exception of the correlation between $\mathrm{M}$ and NC) statistically significant. That is, the negative relationship between tendency to make meaning-preserving errors and other measures of reading performance appeared to be stronger in the control group than in the dyslexic group. In all other respects, however, the pattern of correlations for the dyslexics could not be statistically distinguished from the pattern for the controls.

Table 2 shows the correlation matrix for all 74 dyslexic and normal subjects; Table 3 presents the correlations for the dyslexics alone. Examination of these correlation matrices allows us to replicate the major results from previous studies of normal readers. Since the correlations for the normals and dyslexics did not differ reliably (with the exception of those correlations involving meaning-preserving errors), statistical tests will be reported for the

Table 2

Pooled Correlation Matrix for Dyslexics and Normals $(n=74)$

\begin{tabular}{|c|c|c|c|c|c|c|c|}
\hline & $\mathbf{R}$ & $E$ & NL & NC & $S$ & $\mathbf{M}$ & REAL \\
\hline $\mathbf{R}$ & & $.87^{* *}$ & $.88 * *$ & $.86 * *$ & $.61^{* *}$ & -.19 & .04 \\
\hline E & & & $.79 * *$ & $.73^{* *}$ & $.47 * *$ & $-.22 *$ & $.20^{*}$ \\
\hline NL & & & & $.95^{* *}$ & $.63^{* *}$ & $-.26^{*}$ & .09 \\
\hline $\mathrm{NC}$ & & & & & $.69 * *$ & $-.24 *$ & .03 \\
\hline S & & & & & & -.19 & $-.21 *$ \\
\hline M & & & & & & & .07 \\
\hline
\end{tabular}

Table 3

Correlation Matrix for Dyslexics $(n=37)$

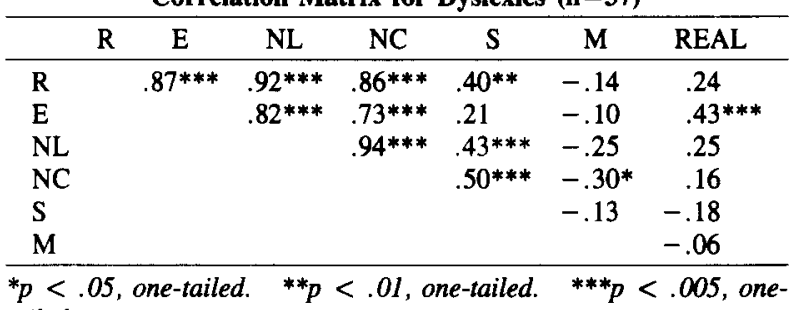

tailed.

pooled data. Consider, first, the correlations among scores on regular, exception, and nonsense words. Although all the correlation coefficients were highly significant, they differed reliably from one another. The correlation between nonsense words and regular words was significantly greater than the correlation between nonsense words and exception words $[t(71)=3.39$ when nonsense words were scored liberally, $t(71)=4.16$ when nonsense words were scored conservatively; $p<.005$ for both, one-tailed]. As discussed by Baron (1979) and Treiman (1984), this result implies that rules are involved in the reading of regular words. Children who are good at rules, or "Phoenician"style readers, use rules to aid performance on regular words as well as on nonsense words. In addition, the correlation between regular words and exception words significantly exceeded the correlation between nonsense words and exception words [ $t(71)=2.78$ for liberal scoring of nonsense words, $t(71)=3.04$ for conservative scoring of nonsense words; $p<.005$ for both, one-tailed]. That ability to read exception words correlates more highly with ability to read regular words than with ability to read nonsense words suggests that word-specific associations, which are needed for exception words, are used for regular words as well. "Chinese"'-style readers, who are good at such associations, use them on both regular words and exception words. Finally, performance on regular words correlated equally highly with performance on nonsense words and performance on exception words. The lack of a difference $[\mathrm{t}(71)=.61$ when nonsense words were scored liberally; $\mathrm{t}(71)=.27$ when they were scored conservatively] implies that spelling-sound rules are not more important than word-specific associations in determining ability to read regular words. These results replicate those observed previously (see Treiman, 1984).

The present results also replicate the finding of earlier studies (see Treiman, 1984) indicating that sound-preserving errors on exception words reflect use of spellingsound rules. These errors correlated significantly more highly with performance on nonsense words and regular words than with performance on exception words. The correlations between $\mathrm{S}$ and NL and $\mathrm{S}$ and $\mathrm{R}$ were indistinguishable $[\mathrm{t}(71)=.63]$, but both exceeded the correlation between $S$ and $E[t(71)=2.88$ and 2.79 , respectively; $\mathrm{p}<.005$, one-tailed, for both]. When nonsense words were scored conservatively, the pattern of results was the same, except that now the correlation between 
$\mathrm{S}$ and $\mathrm{NC}$ exceeded the correlation between $\mathrm{S}$ and $\mathrm{R}[\mathrm{t}(71)$ $=1.87, \mathrm{p}<.05$, one-tailed].

In line with the previous suggestion (Mitterer, 1982), that readers who rely on word-specific associations are more apt to produce real-word errors than are readers who rely on rules, the tendency to make real-world errors correlated reliably with performance on exception words. Proportion of real-word errors correlated significantly more highly with exception-word score than with regular-word score $[\mathrm{t}(71)=2.87, \mathrm{p}<.005$, one-tailed] or with conservative nonsense-word score $[\mathrm{t}(71)=2.06$, $\mathrm{p}<.025$, one-tailed]. [The difference did not reach significance for liberal nonsense-word score, $t(71)=1.56$.]

This study failed to find, as several previous studies have (Baron, 1979; Mitterer, 1982), that "Chinese" readers make more meaning-preserving errors than do "Phoenicians." In the pooled data, the proportion of meaning-preserving errors tended to correlate negatively with reading performance. It did not correlate significantly less negatively with performance on exception words than with performance on regular and nonsense words. Recall, however, that the proportion of meaning-preserving errors was the one variable that showed a pattern of correlations for the dyslexics that was different from that for the normals. For the dyslexics taken alone, there was a trend for meaning-preserving errors to correlate less negatively with exception words than with nonsense words scored conservatively. The difference between the correlation coefficients, however, was not significant $[\mathrm{t}(34)=$ $1.68, \mathrm{p}>.05$, one-tailed].

\section{DISCUSSION}

The present results largely replicate those of Beech and Harding (1984) with a sample of children who were classified as dyslexic. Like Beech and Harding, we found that dyslexics did not perform worse on nonsense words and better on exception words than younger normal children of the same reading level. Rather, the performances of the two groups on nonsense words and exception words were indistinguishable. This result is consistent with the developmental-lag hypothesis but not with the ruledeficiency hypothesis. Unlike Beech and Harding, we also examined dyslexics' and normals' errors on regular, exception, and nonsense words. Sound-preserving errors on exception words were found to correlate with use of rules in reading, but dyslexics did not make reliably fewer of these errors than did normals. Again, this result fails to support the hypothesis that dyslexics are deficient, relative to normals, in the use of spelling-sound rules.

Although the major results from our study were inconsistent with the rule-deficiency hypothesis, two findings from the error analysis appear to support this hypothesis. First, more of the dyslexics' errors than the normals' errors were real words. Since the tendency to make realword errors correlated with use of word-specific associations, this difference seems to suggest that dyslexics are more likely to use associations than are normals. Second, given that dyslexics misread a word as another real word, the error was more likely to be close in meaning to the target than it was for normals. There was a trend (not significant) for meaning-preserving errors to occur among "Chinese"-style readers; therefore, the group difference in these errors could be taken to suggest that dyslexics are more likely to be "Chinese."

Given the striking similarity of the dyslexics and normals in levels of performance on exception and nonsense words and in tendency to make sound-preserving errors, the differences between the groups should not be overvalued. That these dyslexics read nonsense words as well as normals and that they regularized exception words as often as normals indicates that they could and did use spelling-sound rules in our reading test. The two differences in error type between the groups, coupled with the group difference in judgments of familiarity of words, may reflect dyslexics' lack of confidence and fear of failure in any task that requires reading. If dyslexics have difficulty on a given word, they may be less persistent in trying to sound it out and more likely to give a real word answer, which at least has a chance of being correct. If they expect to have difficulty on a word, they may also be more likely to make the excuse that the word is unfamiliar to them. Despite these factors, however, the dyslexics, in fact, succeeded in reading as many itemseven unfamiliar nonsense words-as did control subjects.

The present results are consistent with earlier reports (Beech \& Harding, 1984; Boder, 1973; Mitterer, 1982; Olson et al., 1985) that dyslexics differ among themselves in the processes they use to read individual words. As Mitterer (1982) shows, in his comparison of two extreme groups of poor readers, some poor readers appear to rely on rules, performing well on nonsense words and making many sound-preserving errors and few real-word errors relative to other subjects. Others rely more on word-specific associations, leading to good performance on exception words, fewer sound-preserving errors, and more real-word errors. In the present study, however, individual differences among the dyslexics appeared to be of the same type and magnitude as the differences found among normal children of the same reading level. That is, the normal readers differed from one another as well, and the variations among the dyslexics were not more extreme than the variations among the normals, as the extreme-individual-differences hypothesis would predict. The one exception to the similar pattern of correlations for the two groups occurred in the case of meaning-preserving errors, which appeared to correlate more negatively with other measures of reading in normals than in dyslexics. This difference needs to be replicated, however, because there were so few meaning-preserving errors in this study.

In sum, the present results support the developmentallag hypothesis over the rule-deficiency hypothesis and the extreme-individual-differences hypothesis. Dyslexics in this study and younger children who were matched for ability to read regular words performed very similarly. 
In particular, the dyslexics read nonsense words as well as the normal children did. Dyslexics differed among themselves in their relative reliance on rules versus wordspecific associations, but there was not a preponderance of "Chinese"'-style readers among the dyslexics, as the rule-deficiency hypothesis would have predicted. Nor was there a tendency for dyslexics to show extreme patterns of performance, as the extreme-individual-differences hypothesis would have predicted.

Although the present results and those of Beech and Harding (1984) support the developmental-lag hypothesis, several previous reports (Bradley \& Bryant, 1978, 1981; Di Benedetto et al., 1983; Kochnower et al., 1983; Olson et al, 1985; Snowling, 1980, 1981) are more consistent with the rule-deficiency hypothesis. The differences in results may arise for several reasons. One possible source is the differences among studies in the criteria for labeling a child as dyslexic (the term used in some studies) or as reading disabled (a term used in other studies). Since reading-disabled children do differ from one another, subtle sampling differences among studies could lead to different group results. However, differences in the age or reading level of the dyslexic samples do not account in any straightforward way for the discrepancies. It might be predicted, based on the view that spelling-sound rules are primarily important at early stages of reading acquisition (Jorm \& Share, 1983; Rozin \& Gleitman, 1977), that the least able dyslexic readers would show the clearest deficiency in use of these rules. If the deficit were later overcome, the older dyslexics might still lag in the development of reading skills but might not differ qualitatively from normal children. However, the dyslexics in the present study, who showed no rule deficit as a group, were not older than the dyslexics studied by Snowling (1980) or Olson et al. (1985), who showed such a deficit. Also, even the poorer dyslexic readers in the present sample pronounced the nonsense words as well as their matched control subjects.

Task differences might help to explain the discrepancies among the various studies. It is possible that dyslexics do have some type of deficiency in using spelling-sound rules, but that this deficiency is not apparent in the kinds of tests used by us and by Beech and Harding (1984). Snowling (1981), for example, has suggested that dyslexics have particular difficulty reading nonsense words of more than one syllable, especially if they contain consonant clusters. Most of the nonsense words in this study had one syllable, and this fact might help explain the dyslexics' good performance. Another factor that might have boosted the dyslexics' performance on nonsense words in this study and in Beech and Harding's study is that the nonsense words were presented in combination with similar regular and exception words. The prior presentation of related real words may have helped the children with the nonsense words.

Even if dyslexics' ability to read nonsense words as well as normal children of the same reading level is confined to certain types of nonsense words or to certain manners of presentation, our results suggest that in some circumstances children who are identified as dyslexic are able to read these items. This finding implies that dyslexics do not necessarily suffer from a general inability to use spelling-sound rules. The dyslexics in this study were certainly delayed in the development of ability to use spellingsound rules-they read nonsense words, on the average, only as well as a group of normal readers who were more than 3 years younger. However, the dyslexics, as a group, were equally delayed in the development of word-specific associations. Their reading performance was quantitatively different from that of the normal children in that it lagged behind, but it did not appear to be qualitatively different.

The present results, along with those of Beech and Harding (1984), suggest that we should not accept uncritically the widespread notion that dyslexics suffer from a specific deficiency in phonological coding and spellingsound rule use. Further research is needed to specify which poor readers manifest such a deficit, and under which conditions. A phonological deficit does not seem to be a universal characteristic of children who are identified as dyslexic. Our results also call into question the view that dyslexia is a syndrome that is clearly distinguishable from poor reading more generally. The reading performance of children identified as dyslexic may not, in fact, be very different from the performance of normal children just learning to read or from the performance of children whose difficulties in reading are considered to stem from low intelligence or poor education. If dyslexic children do not show patterns of reading performance that are clearly different from those of young or poor readers, then the classification of these children as suffering from a specific and unique disorder may itself be misleading. Furthermore, the remedial methods found to be appropriate for children who are labeled as dyslexic may also be appropriate for children who are depressed in reading because of low intelligence or poor education.

\section{REFERENCES}

BARON, J. (1977). Mechanisms for pronouncing printed words: Use and acquisition. In D. LaBerge \& S. J. Samuels (Eds.), Basic processes in reading: Perception and comprehension (pp. 175-216). Hillsdale, NJ: Eribaum.

BARON, J. (1979). Orthographic and word-specific mechanisms in children's reading of words. Child Development, 50, 60-72.

Baron, J., \& Strawson, C. (1976). Use of orthographic and wordspecific knowledge in reading words aloud. Journal of Experimental Psychology: Human Perception and Performance, 2, 386-393.

BarON, J., \& TREIMAN, R. (1980a). Some problems in the study of differences in cognitive processes. Memory \& Cognition, 8, 313-321.

BARON, J., \& TREIMAN, R. (1980b). Use of orthography in reading and learning to read. In J. F. Kavanagh \& R. L. Venezky (Eds.), Orthography, reading, and dyslexia (pp. 171-189). Baltimore: University Park Press.

BeECH, J. R., \& HaRding, L. M. (1984). Phonemic processing and the poor reader from a developmental lag viewpoint. Reading Research Quarterly, 19, 357-366.

BODER, E. (1973). Developmental dyslexia: A diagnostic approach based on three atypical reading-spelling patterns. Developmental Medicine and Child Neurology, 15, 663-687. 
Bradley, L., Bryant, P. (1978). Difficulties in auditory organisation as a possible cause of reading backwardness. Nature, 271, 746-747,

Bradley, L., \& Bryant, P. (1981). Visual memory and phonological skills in reading and spelling backwardness. Psychological Research, 43, 193-199

CARR, T. H. (1981). Building theories of reading ability: On the relation between individual differences in cognitive skills and reading comprehension. Cognition, 9, 73-114.

CARroll, J. B., Davies, P., \& Richman, B. (1971), Word frequency book. New York: American Heritage.

Coltheart, M. (1978). Lexical access in simple reading tasks. In G. Underwood (Ed.), Strategies of information processing (pp. 151-216). London: Academic Press.

DiBenedetto, B., Richardson, E., \& Kochnower, J. (1983). Vowel generalization in normal and learning disabled readers. Joumal of Educational Pscyhology, 75, 576-582.

FrEYD, P., \& Baron, J. (1982). Individual differences in acquisition of derivational morphology. Journal of Verbal Learning and Verbal Behavior, 21, 282-295.

GiLmore, J. V., \& GiLmore, E. C. (1968). Gilmore oral reading test. New York: Harcourt, Brace, and World.

HiRSh-PASEK, K., \& FREYD, P. (1984, October). Taking the latin and Greek out of English: Morphological analysis by hearing and deaf readers. Paper presented at the Boston University Conference on Language Development, Boston.

JORM, A. F. (1979). The cognitive and neurological basis of developmental dyslexia: A theoretical framework and review. Cognition, 7 , 19-33.

Jorm, A. F., \& Share, D. L. (1983). Phonological recoding and reading acquisition. Applied Psycholinguistics, 4, 103-147.

Kochnower, J., Richardson, E., \& DiBenedetTo, B. (1983). A com parison of the phonic decoding ability of normal and learning disabled children. Journal of Learning Disabilities, 16, 348-351.

Mitterer, J. O. (1982). There are at least two kinds of poor readers: Whole-word poor readers and recoding poor readers. Canadian Journal of Psychology, 36, 445-461.

Morrison, D. F. (1976). Multivariate statistical methods (2nd ed.) New York: McGraw-Hill.

Olson, R. K., KLiEGL, R., Davidson, B. J., \& FoltZ, G. (1985) Individual and developmental differnces in reading disability. In T. $G$ Waller (Ed.), Reading research: Advances in theory and practice (Vol 4, pp. 1-64). New York: Academic Press.

Rozin, P., \& Gleitman, L. R. (1977). The structure and acquisition of reading. II: The reading process and the acquisition of the alphabetic principle. In A. S. Reber \& D. L. Scarborough (Eds.), Toward a psychology of reading: The proceedings of the CUNY conference (pp. 55-141). Hillsdale, NJ: Erlbaum.

SNOWLING, M. J. (1980). The development of grapheme-phoneme correspondence in normal and dyslexic readers. Journal of Experimental Child Psychology, 29, 294-305.

SNowling, M. J. (1981). Phonemic deficits in developmental dyslexia. Psychological Research, 43, 219-234.
Treiman, R. (1984). Individual differences among children in spelling and reading styles. Journal of Experimental Child Psychology, 37, 463-477

Treiman, R., Baron, J. (1981). Segmental analysis ability: Development and relation to reading ability. In G. E. Mackinnon \& T. G Waller (Eds.), Reading research: Advance in theory and practice (Vol. 3, pp. 159-198). New York: Academic Press.

Woodcock, R. W. (1973). Woodcock reading mastery test. Circle Pines, $\mathrm{MN}$ : American Guidance.

\section{NOTES}

1. Males were used because other research being carried on at CMDN] at the time was restricted to males, so that only the boys who were referred to the clinic were followed and tested.

2. To have matched the normal readers with the dyslexics for sex as well as for regular word score would have made it much more difficult to find control subjects. Since a previous study using the same reading test employed here (Treiman, 1984) did not find evidence for a sex difference in reading style, matching on sex was not considered essential.

\section{APPENDIX \\ List of Stimuli in Order of Presentation}

DOME (R), DAYS (R), GAVE (R), COUNTER (R), BONE (R), RATHER (R), HOLE (R), NEW (R), ALONG (R), PLEAT (R), HOE (R), COME (E), SAYS (E), HAVE (E), COUNTRY (E), DONE (E), FATHER (E), HOUR (E), SEW (E), AMONG (E), GREAT (E), SHOE (E), GOME (N), TAYS $(\mathrm{N})$, TAVE $(\mathrm{N}), \operatorname{COUNTLY}(\mathrm{N})$, YONE $(\mathrm{N}), \operatorname{DATHER}(\mathrm{N})$, HOUL (N), REW (N), ANONG (N), PREAT (N), VOE (N), SNEAK (R), MAID (R), BROOD (R), WHILE (R), MOTH (R), ROSE (R), CLOSER (R), LONE (R), POUCH (R), GROAN (R), POLITE (R), STEAK (E), SAID (E), BLOOD (E), WHOLE (E), BOTH (E), LOSE (E), CLOSET (E), GONE (E), TOUCH (E), BROAD (E), POLICE (E), SMEAK (N), HAID $(\mathbb{N})$, SLOOD $(\mathbb{N})$, WHULE $(N)$, POTH $(\mathbb{N}), \operatorname{WOSE}(N)$, CLOSEN (N), SONE (N), ROUCH (N), GROAD (N), POLINE (N), CHAIR (R), FOUL (R), CHOKE (R), TOWERS (R), TREATED (R), SPARSE (R), CONTAIN (R), PELLET (R), HARPS (R), URCHIN (R), CHORD (E), SOUL (E), CHUTE (E), TOWARD (E), CREATED (E), SCARCE (E), CURTAIN (E), BALLET (E), CORPS (E), ORCHID (E), CHOID (N), NOUL (N), CHUKE (N), TOWARK (N), GLEATED (N), SCARSE (N), CORTAIN (N), DALLET (N), HORPS $(\mathrm{N})$, ORCHIN $(\mathrm{N})$.

(Manuscript received November 26, 1984; revision accepted for publication March 21, 1985.) 